Please cite as: Hafford-Letchfield, T., Cocker, C., Rutter, D., Manning, R., McCormack, K (2020) Doing the right thing and getting it right: Professional perspectives in social work on supporting parents from gender diverse communities. International Journal of Transgender Health. Published online first https://www.tandfonline.com/doi/full/10.1080/26895269.2020.1831417

\title{
Title: Doing the right thing and getting it right: Professional perspectives in social work on supporting parents from gender diverse communities
}

\begin{abstract}
Background: Despite significant shifts in legislative, political, cultural and social contexts, which have improved our understanding of diverse gender identities and familylife, this remains under-explored_within social work and social care. Trans and non-binary (TNB) parenting experiences are marginalised within mainstream professional practice and action is required to address these inequalities.
\end{abstract}

Aims: This study explored the practices and meaning of 'parenting' and 'caring' for care professionals in families with parents with diverse gender identities in the UK. It aimed to capture a snapshot of the current state of practice knowledge and perceived practice challenges.

Methods: A qualitative study design involving thematic analysis from detailed consultation with twenty-five relevant stakeholders in the proxy roles identified from a systematic review (authors own, 2019) on what is known about trans parenting from the research evidence.

Results: The complexity of systems for supporting families creates barriers to change, with a lack of training and development in the knowledge and skills of the workforce. Intersecting these themes was a strong values framework and examples of best practice provided, which social workers can use to navigate, understand, and support TNB parents and their experiences, particularly at an individual level, as a means to effect change.

Discussion: Focussing on human rights, tailoring work to the specific needs of individuals and families, and affirming the diversity of family life requires professionals to take active responsibility and be more accountable in educating themselves and others on these rights. 
Please cite as: Hafford-Letchfield, T., Cocker, C., Rutter, D., Manning, R., McCormack, K (2020) Doing the right thing and getting it right: Professional perspectives in social work on supporting parents from gender diverse communities. International Journal of Transgender Health. Published online first https://www.tandfonline.com/doi/full/10.1080/26895269.2020.1831417

Professionals also need to reach out to the TNB community to include them in improving services as well as being active in their own organisations to ensure these are inclusive and responsive.

Keywords: Trans; non-binary; parenting; caring; social work; social care; support

\section{Introduction}

Significant shifts in legislative, political, cultural and social contexts have improved our understanding of diverse gender identities and family life. Their impact, however, is underexplored within social work and social care in the UK, and any nuances in working with families with gender diverse parents are marginalised within mainstream professional practice. This paper seeks to assess the state of knowledge and skills in current practice, and explores motivators and barriers to achieving step-change in family care where there are trans and non-binary (TNB) parents and carers. Based on themes from a systematic review (Authors own) of the empirical evidence about parenting and caring by and with people with diverse gender identities, and in the absence of any practice guidelines, we sought to open up constructive dialogue with professionals to identify, prioritise and agree upon the areas in which practice needs to develop and improve. The findings inform our understanding of readiness for change and what is needed for professionals to engage with change, including the identification of teachable moments, which reflect good practice.

This study makes a theoretical contribution to understanding caring practices in families by exploring sexual and gender citizenship along with social justice. By addressing counter cultural hegemonic narratives about family life; personal and family intimacies can be identified, discussed and given meaning with social workers and other professionals where 
Please cite as: Hafford-Letchfield, T., Cocker, C., Rutter, D., Manning, R., McCormack, K (2020) Doing the right thing and getting it right: Professional perspectives in social work on supporting parents from gender diverse communities. International Journal of Transgender Health. Published online first https://www.tandfonline.com/doi/full/10.1080/26895269.2020.1831417

these are under-recognised (Hines, 2007). The authors come from a social constructionist position, seeking to challenge heteronormative and cisgenderist professional practice with families in care services, and capitalise on the growing positive research evidence on the quality of parenting provided in LGBT+ communities (Authors own) (Golombok et al., 2014; Golombok \& Tasker, 1996; Hicks, 2014). Globalised socio-cultural trends such as the decrease in fertility rates, fertility treatments, legislative changes to partnerships and shifting trends in family expectations (Walls, Kattari, \& DeChants, 2018; Walls, Kattari, Speer, \& Kinney, 2019) have altered the landscaping of parenting and its intersectional nature. This demands a considered practice response. TNB individuals may choose adoption, fostering (Brown \& Rogers, 2020), surrogacy, harvesting genetic material, and giving birth, whether before or after transition and be partnered with someone who has children (Obedin-Maliver \& Makadon, 2016; Poly \& Poly, 2014; Walls et al., 2019).

This paper describes how we explored these themes through in-depth consultation directly with a range of proxy stakeholders and leaders in social work and other care services discussed in the existing literature. This involved; disseminating the findings from a systematic review (authors own), discussing the issues with key stakeholders; identifying and synthesizing themes with the evidence and values emerging from practice expertise and experience. This enabled the benchmarking of good practice examples, outlined in the form of case studies, driven by individual professionals committed to making a difference to services for TNB families. We also identified a number of challenges that reinforce the dangers of heteronormative and cisnormative polices and frameworks continuing to govern practice and some options for moving forward.

\section{Background}


Please cite as: Hafford-Letchfield, T., Cocker, C., Rutter, D., Manning, R., McCormack, K (2020) Doing the right thing and getting it right: Professional perspectives in social work on supporting parents from gender diverse communities. International Journal of Transgender Health. Published online first https://www.tandfonline.com/doi/full/10.1080/26895269.2020.1831417

In the UK, transgender and non-binary (TNB) parents have been in the media spotlight following popularist interest in trans pregnancy (Pearce, Moon, Gupta, \& Steinberg, 2020) and high profile cases in the High Court. A relative silence in the social work professional community on these situations in public and private law should draw attention to their roles in providing advocacy and support to the different members and their interests, within the families involved. Case law has challenged legal inconsistencies on trans parental rights by exposing incompatibilities of the Children Act (1989) with the Gender Recognition Act (2004) and Human Rights Act (2010) particularly in relation to Article 8, (Rights to Family Life). One example is Freddy McConnell, a transgender man who gave birth in 2018 following fertility treatment. McConnell lost his appeal to be legally registered as his child's 'father' or otherwise 'parent' or 'gestational parent' rather than 'mother'. With a Gender Recognition Certificate, McConnell argued that not being registered as a father on his child's birth certificate was breach of his right to a private and family life under Article 8 of the Human Rights Act ("R (on the application of McConnell and another) v Registrar General for England and Wales," 2019).

Scholarship and UK policy on LGBT+ parenting, has focused less on TNB even though a sizable portion of the community are already parents or interested in becoming a parent (Brown \& Rogers, 2020; Pearce \& White, 2019; Tasker \& Gato, 2020). It is often the case, however, that the different needs and experiences of ' $\mathrm{T}$ ' parents, especially pregnant trans people, are still not considered or accounted for (White, 2018). For example, gendered language and the legal categories for parenthood are mostly cis-normative. Unlike lesbian and gay parenting, there has been little progress in actual practice development related to 
Please cite as: Hafford-Letchfield, T., Cocker, C., Rutter, D., Manning, R., McCormack, K (2020) Doing the right thing and getting it right: Professional perspectives in social work on supporting parents from gender diverse communities. International Journal of Transgender Health. Published online first https://www.tandfonline.com/doi/full/10.1080/26895269.2020.1831417

TNB parents and a dearth of research on bisexual and intersex parenting (Bowling, Dodge, \& Bartelt, 2017; Patterson, 2017).

\section{Transgender and non-binary parenting in the UK}

There are no official estimates of the size or growth of the TNB population in the UK, due to conceptual and practical issues surrounding the collection of data (Office for National Statistics, 2017). Best estimates are that $1 \%$ might identify as trans of which $0.4 \%$, confirmed a non-binary gender identity (Stonewall, nd). Without accepted estimates, service planning is impaired and the needs of the community under-resourced. Those with Gender Recognition Certificates following the Gender Recognition Act (GRA, 2004) by no means reflects the population. This process is described as an outdated, stressful, dehumanising, medicalised and traumatic for trans people to go through (White, 2018). A government consultation in 2019 on GRA reform has not reported (Ministry for Equalities, 2018) following two reviews of transgender equality (House of Commons Women and Equalities Committee, 2016) and provision of gender identity services ( (NHS England, 2017) (see White, 2018). A legislative and policy review in the UK (White, 2018) revealed that in the GRC (2004), there is an absence of consideration for trans people as parents in any capacity and no reference to non-binary (NB) people as parents (due to the absence of provisions in the GRA). A brief exception in Section 12 states that 'acquired gender' under the Act does not affect the status of the person as the father or mother of a child as illustrated in the case of Freddy McConnell.

In the few examples on TNB experiences (see reviews by (Communities Analytical Services, 2013; House of Commons Women and Equalities Committee, 2016; Hudson-Sharp \& Metcalf, 2016; Mitchell \& Howarth, 2009), significant levels of inequality across all policy 
Please cite as: Hafford-Letchfield, T., Cocker, C., Rutter, D., Manning, R., McCormack, K (2020) Doing the right thing and getting it right: Professional perspectives in social work on supporting parents from gender diverse communities. International Journal of Transgender Health. Published online first https://www.tandfonline.com/doi/full/10.1080/26895269.2020.1831417

areas and in the provision of public services have been demonstrated. These include discrimination and transphobia in schools, social services, the National Health Service (NHS), prisons and probation services, the police and in refuges for vulnerable women leaving unsafe situations. Some of these are illustrated in the high number of trans people having experienced a hate crime in the past year (41\%), and in those who have experienced domestic abuse from a partner (25\%) (Garthe et al., 2018; White, 2018).

A rapid evidence review and limited empirical work (Hudson-Sharp, 2018) sought to ascertain the adequacy and consistency of education and practice development in social work with TNB families. Findings revealed a significant lack of TNB-specific social work research and practice, resulting in poor experiences for TNB individuals and families alongside everyday discrimination and gaps in services (Alleyn \& Jones, 2010; Government Equalities Office, 2016). Few social workers receive specific education or training on TNB issues (Craig, Iacono, Paceley, Dentato, \& Boyle, 2017). This lack of specificity and inclusivity for families with TNB individuals, and the tendency to work with deficit models, are further undermined by a lack of resources regarding TNB issues and the lack of networking for TNB families or by practitioners working with TNB families, (Authors own 2020).

\section{Published research on TNB parents}

A systematic review published in 2019 (Authors own) of the published empirical research about TNB parents found twenty-six studies, with just two directly involving UK citizens. Themes from these studies illustrated the complexities for TNB parents within the context of their existing family relationships and personal commitments. A myriad of challenges documented the impact on children, relationships with partners and wider families within a 
Please cite as: Hafford-Letchfield, T., Cocker, C., Rutter, D., Manning, R., McCormack, K (2020) Doing the right thing and getting it right: Professional perspectives in social work on supporting parents from gender diverse communities. International Journal of Transgender Health. Published online first https://www.tandfonline.com/doi/full/10.1080/26895269.2020.1831417

transphobic and discriminatory culture. There were no studies on grandparents and grandchildren. The review highlighted shortcomings regarding care working with trans individuals in care practice. These concerned attitudes, lack of critical reflexivity, knowledge and skills to work with issues affecting families with TNB parents and carers. Findings also demonstrated that parents were as invested and committed to their loved ones as any other persons, and many experienced positive relationships with their children (Stotzer, Herman, \& Hasenbush, 2014). Like cisgender and sexually diverse parents, TNB parents and carers reported the need for opportunities to connect with other families and support services for their children (Stotzer et al., 2014). In their wish to be authentic, there was fear of alienating and destroy familial bonds, giving rise to internalised stigma, fear of failure and lack of disclosure about their support needs (Lev, 2004)(p. 314). Ongoing personal, interfamilial and systemic barriers in their family lives were also reinforced through a transphobic context and a lack of appropriate services, targeted support and advocacy (Gapka \& Raj, 2003). TNB parents are also more likely to experience discrimination based on their gender identity in custody agreements, courts, and adoption processes (Pyne, Bauer, \& Bradley, 2015; Stotzer et al., 2014). Services for prospective parents were poorly equipped to serve the unique reproductive needs of trans people, with significant barriers including adoption and fostering services (Brown \& Rogers, 2020; Hines, 2006). These review themes needed to be explored, from the perspectives of professionals on the ground.

\section{Method}

This was an exploratory study with the following questions: 
Please cite as: Hafford-Letchfield, T., Cocker, C., Rutter, D., Manning, R., McCormack, K (2020) Doing the right thing and getting it right: Professional perspectives in social work on supporting parents from gender diverse communities. International Journal of Transgender Health. Published online first https://www.tandfonline.com/doi/full/10.1080/26895269.2020.1831417

1. What experiences do social work and care practitioners have in working with TNB parents and carers and what knowledge, skills and expertise do they feel they need?. What do they see as the current strengths and gaps?

2. What are the anticipated challenges at the macro and micro level for organisations in identifying and providing support to TNB parents and carers and in making services accessible and responsive?

3. What can we learn from practice that will help to inform the development of best practice for social work and social care useful for their day-to-day work?

\section{Study design}

This study conducted an in-depth consultation with relevant key stakeholders and leaders in care services guided by the systematic review themes, to establish their relevance, application and meaning for professional practice. As a research team comprised of members with expertise in social work, mental health, lesbian and gay parenting, and trans activists with lived experience, our objectives were agreed co-productively. We followed ethics and principles (Adams et al., 2017; Marshall et al., 2017; Vincent, 2018) documented by trans researchers which calls for transparency and knowledge democracy in developing research with explicit and positive impact on trans lives. Having conducted a review documenting studies on TNB parents, members of the team expressed reservations about duplication and over-research that can be harmful to trans and NB populations (Marshall et al, 2017). Reframing our 'target population' as co-producers of knowledge (Orr \& Bennett, 2009) opened up what we can potentially learn by listening on how to effectively engage with TNB communities . Listening is the most powerful tool of the emancipatory researcher (Vincent, 
Please cite as: Hafford-Letchfield, T., Cocker, C., Rutter, D., Manning, R., McCormack, K (2020) Doing the right thing and getting it right: Professional perspectives in social work on supporting parents from gender diverse communities. International Journal of Transgender Health. Published online first https://www.tandfonline.com/doi/full/10.1080/26895269.2020.1831417

2018). Having worked together and built trust during the systematic review, we identified professionals as under-researched.

Involving members of the community as peer researchers can result in emotional labour (Pearce, 2020; Vincent, 2018). Our team members with lived experience were paid and involved as researchers and advisors throughout, including study design, putting together the pilot questionnaire, choice of research method and participants targeted. They participated in data collection, and had access to the data and data analysis. The latter was impacted by their time limitations and work demands. We communicated regularly to support each other.

A broad topic guide based on themes from the review, enabled the interviewer to explore and identify issues in practice through a process of problem setting; identifying challenges and enablers; reviewing and selecting relevant knowledge for the participant's specific roles and contexts in relation to the topic. We conducted a focus group (author 1 and 5) and individual interviews (authors 1, 2, 3, 4 and 5) using a reflective, critical approach to fieldwork, which encouraged discussion amongst a large range of stakeholders, as to the adequacy of practice. Questions included: How are issues about gender identities being raised in practice? When do the opportunities arise for conversations around gender and sexual identities arise in their practice? How does the team/service/organisation record and use information about gender identity issues identified in their work with families and carers? What priorities are given to improving practice in this area?

Ethical approval was provided by x University. Funding was allocated to compensate any TNB research participants for their time where required, as recognition of using institutional power to benefit the trans community and building rapport (Vincent, 2018, p104) 
Please cite as: Hafford-Letchfield, T., Cocker, C., Rutter, D., Manning, R., McCormack, K (2020) Doing the right thing and getting it right: Professional perspectives in social work on supporting parents from gender diverse communities. International Journal of Transgender Health. Published online first https://www.tandfonline.com/doi/full/10.1080/26895269.2020.1831417

\section{Participant sample}

Recruitment involved a combination of purposive, opportunist and snowball methods to reach participants who could act as informants, consultants, advisors and critical friends. This depended on contacts of members in the team and our professional and community networks. Working from a list of proxy roles, we actively sought out viewpoints or functions in the field thought to have responsibilities and influence on the key issues reflected in the review

findings. Table 1 provides an overview of the twenty-five individuals that participated from social work, health, mental health, members of a regional genderinclusion services from different disciplines, academics with responsibilities of training professionals and people with lived experience of parenting and included those involved in making local policies.

Table 1: Overview of study participants

Professional Discipline

Social Work
Area of speciality/role

A senior social work leader
No of participants

11 
Please cite as: Hafford-Letchfield, T., Cocker, C., Rutter, D., Manning, R., McCormack, K (2020) Doing the right thing and getting it right: Professional perspectives in social work on supporting parents from gender diverse communities. International Journal of Transgender Health. Published online first https://www.tandfonline.com/doi/full/10.1080/26895269.2020.1831417

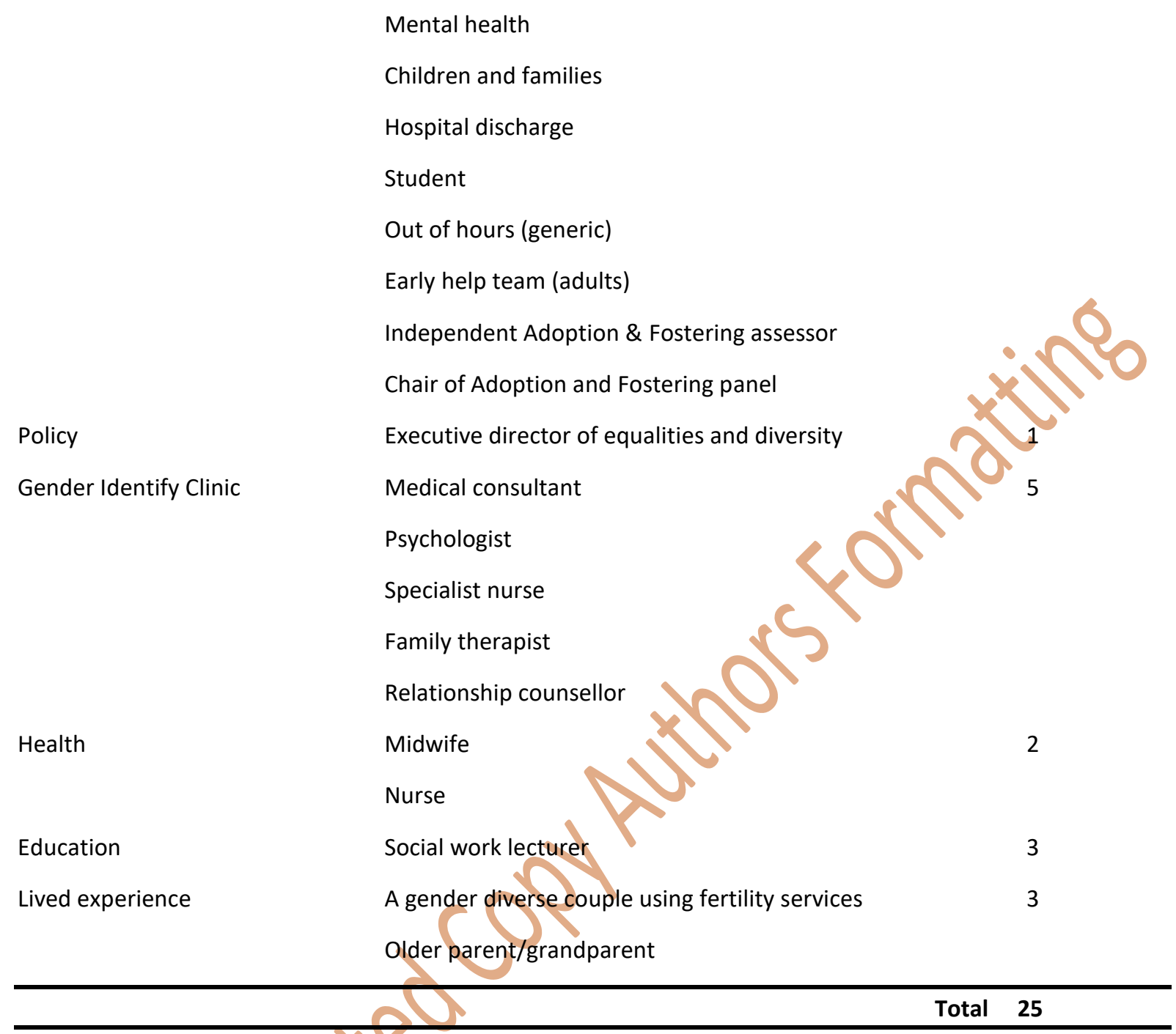

\section{Data analysis}

Discussions were digital recorded and professionally transcribed. Every transcript was read by both authors 1 and 3 and an inductive coding framework agreed. Author 3 coded all of the data manually with author 1 checked for validity. A meeting to discuss the coded data enabled the development of a broad thematic analysis. We extracted emergent themes, put into tables together with the source transcripts, and shared with team members (authors 2, 4 and 5) for wider comment and consensus. This final stage led to team members providing a list of summary points on each of the themes. Further, author 3, developed case studies linked 
Please cite as: Hafford-Letchfield, T., Cocker, C., Rutter, D., Manning, R., McCormack, K (2020) Doing the right thing and getting it right: Professional perspectives in social work on supporting parents from gender diverse communities. International Journal of Transgender Health. Published online first https://www.tandfonline.com/doi/full/10.1080/26895269.2020.1831417

to one or more transcripts. Discussion of these themes in the results section is illustrated using participant quotes.

\section{Results}

The data provided broad and rich themes in relation to the participants' direct experience of TNB parenting, how this was recognised and reflected in wider policies and practice with families, the complexity of organisational and systems which can create barriers to change, and the challenges in training and developing the knowledge and skills of the workforce. Intersecting these themes was a strong values framework, which participants used to navigate their understanding of how best to understand and support TNB parents in the absence of a corporate or local coherent response to individual and family needs. This focused on how they as individuals could challenge or improve people's experiences when they interacted with care services. We present the data using three themes: moving from 'niche' to inclusive practice; investing and developing knowledge and skills of professionals, and building trust.

\section{Practice experiences: moving from 'niche' to inclusive practice}

Many participants expressed the view that work with TNB parents was seen as a 'niche' area of practice, and were unsure of which universal services TNB parents and carers currently use and which they could or might access. Participants thought that TNB individuals were hidden or marginalised from mainstream parenting services, but stressed that explicit public service values familiar to professionals working in care services should underpin all universal services. The gender identity of a parent requiring support and accessing services should not matter in this context. 
Please cite as: Hafford-Letchfield, T., Cocker, C., Rutter, D., Manning, R., McCormack, K (2020) Doing the right thing and getting it right: Professional perspectives in social work on supporting parents from gender diverse communities. International Journal of Transgender Health. Published online first https://www.tandfonline.com/doi/full/10.1080/26895269.2020.1831417

Gender identity was identified as a cross cutting theme for a range of services needed to support families, with the understanding that this would need to be cross-disciplinary and interprofessional. Some discreet examples of direct work with trans individuals as parents were given in mental health and disability services, following healthcare referrals. Social work participants noted that socio-economic issues and class were likely to drive help seeking, however demands on resources make the threshold for involvement in children and families social services high and exclude criteria for specific support. Therapeutic interventions related to family dynamics and relationship issues that trans parents faced were described as scarce. The examples given of direct work with TNB families involved complex vulnerabilities such as mental health, drug use, physical health problems and family conflicts and practitioners felt these issues affected the way in which interventions were provided to trans parents, with gender identity problematized, and seen as the over-riding factor requiring 'specialist' support.

One professional in a Gender Identity clinic stated that TNB parents contact with specialist services are actually relatively brief, but TNB parents are likely to be in contact with everyday services, which all need to have the capabilities to work with them.

"(However) in the present climate professionals seem to act irrationality when TNB people and parents are involved and it's difficult for TNB parents and advocates to know if responses are discriminatory" (Gender Identity Clinic Nurse) .

Some social care professionals pointed out the relatively rare examples of local authority involvement with TNB parents and families. These participants noted that this limited service user contact was a barrier to keeping their knowledge up to date and 'have that dialogue' (Practice lead, Local Authority). 
Please cite as: Hafford-Letchfield, T., Cocker, C., Rutter, D., Manning, R., McCormack, K (2020) Doing the right thing and getting it right: Professional perspectives in social work on supporting parents from gender diverse communities. International Journal of Transgender Health. Published online first https://www.tandfonline.com/doi/full/10.1080/26895269.2020.1831417

One participant, in responding to other professionals who found it challenging to work with trans or non-binary people, suggested a response that used a broad categorisation of diversity and equality issues and their effect on professional practice. They noted that:

"if you took away the word trans and put anything else in there, HIV positive, gay, black, Muslim, Christian, .....people wouldn't find it so challenging" (mental health social worker)

This intersection of diversities for individual TNB people can also become problematic in how practitioners respond to multiple needs. A student social worker doing his placement in mental health services described being advised by his supervisor to secure a diagnosis of autistic spectrum to make it easier for a trans parent to access services when they presented with mental health issues associated with transition. Mental health service participants acknowledged the notable incidences of people struggling with their gender identity in their services, and identified a need for all staff to have a better understanding of the specific issues facing TNB people in their lives, to improve overall service provision.

\section{Investing and developing the knowledge and skills of professionals: qualifying and post- qualifying education, and ongoing work-based support:}

Most participants agreed that everyone in the social care and health workforce should have a certain amount of knowledge and skills to adapt their assessments and provision within their service. They saw this primarily as an issue of cultural competency and a responsibility of practitioners to manage their own biases, judgements, and expectations in a professional capacity. This was, however, evidenced as fraught in multidisciplinary work, where examples were given of different professionals being unclear about why they were working 
Please cite as: Hafford-Letchfield, T., Cocker, C., Rutter, D., Manning, R., McCormack, K (2020) Doing the right thing and getting it right: Professional perspectives in social work on supporting parents from gender diverse communities. International Journal of Transgender Health. Published online first https://www.tandfonline.com/doi/full/10.1080/26895269.2020.1831417

with a trans person. Consequently, instead of focusing on the presenting issues, gender identity was again problematised.

Knowledge and skills are gained through direct experience and training. Participants described limited experiences of working with TNB communities, further compounded by the rarity of opportunities for training and staff development. Only one participant reported receiving any training in their professional training programme. As a student with lived experience, with no input on gender diversity in their professional qualifying programme, he initiated a student-led one-day workshop, supported by the university. Participants responsible for professional education referred to gender diversity as a topic that 'should be addressed' within learning content on equality and diversity supported by vignettes or case studies albeit, it was often not. They described the teaching of transferable skills concerning non-discriminatory practice, empathy, acceptance, unconditional positive regard that are applicable for working with TNB parents.

TNB themes were not addressed in learning about legislation and social policy to equip students from multi-disciplinary backgrounds to provide effective advocacy and referrals. Further, academics noted the need to address gender diversity from a life-course perspective in relation to the significance of family relationships for trans parents throughout their lives, including support needs in later life. They referred to theoretical frameworks such as loss, bereavement and conflict, which were important for working with the TNB community.

The midwifery tutor anticipated that their students are:

"not likely to meet someone in this situation very often and I would tend to use a trans example in the taught curriculum about diverse families but Ifeel more cautious 
Please cite as: Hafford-Letchfield, T., Cocker, C., Rutter, D., Manning, R., McCormack, K (2020) Doing the right thing and getting it right: Professional perspectives in social work on supporting parents from gender diverse communities. International Journal of Transgender Health. Published online first https://www.tandfonline.com/doi/full/10.1080/26895269.2020.1831417

about introducing into the practice curriculum in an area where there are likely to be religious objections".

This comment acknowledges challenges that go under the radar in practice where the workforce are not equipped to assert the rights of trans people. One social work academic noted that critical reflection and examination of one's own prejudices is an essential prerequisite for preparing students for curious and assertive practice, and that unlearning for some students has to take place in safe spaces given what personal prejudices or ignorance they may bring into their practice. Again, the unaddressed religious beliefs of learners were mentioned as a barrier (authors own).

Many participants referred to the lack of quality learning materials depicting trans lives or how to access these (authors own, 2017). Other participants were genuinely unsure of where to get good quality information, mentioning 'Stonewall', the 'Tavistock', the internet and general media as sources they used. Further, educators themselves did not feel confident in developing curriculum that was multi-disciplinary, and lacked confidence or time to assert the prioritising of trans issues in what is seen as an overladen and prescribed national curriculum:

" the majority of them don't use services and therefore if you don't define them as service users, you lose the essence of having them included in social work education" (social work academic)

Finally, participants with responsibility for education noted opportunities to engage members of the trans community in developing learning resources and delivering education within their service user education strategies. One educator gave positive examples of using novels to 
Please cite as: Hafford-Letchfield, T., Cocker, C., Rutter, D., Manning, R., McCormack, K (2020) Doing the right thing and getting it right: Professional perspectives in social work on supporting parents from gender diverse communities. International Journal of Transgender Health. Published online first https://www.tandfonline.com/doi/full/10.1080/26895269.2020.1831417

stimulate discussion on gender identity and utilised trans users narratives in the 'Human Library' to stimulate student discussion and debate.

Given that training and education is often practice-based, significant emphasis was placed on the use of supervision in the workplace and encouraging learners to research their own practice relating to situations service users present with. Practitioners referred to the use of reflective practice and professional values as a good starting point for people to ask the right questions and look for strengths in a family where a member is TNB. Again emphasis on problem solving or practical tasks had the potential to squeeze out the promotion of wellbeing and emotional impact due to pressure on resources. This reinforced earlier themes from professionals who perceived the need to problematise trans parents experiences in order to secure resources.

\section{Building trust in working practices with TNB parents}

Many participants confirmed that gender and sexual identities are widely confused or conflated when a TNB person approaches services. Being able to confidently and competently explore people's histories and narratives using appropriate language and skill was described as fundamental to building trust and relationships with TNB parents to aid their subsequent access and use of services. At the other end of the spectrum, an 'out of hours' social worker noted a naïve approach from colleagues. He stated:

"As a gay man, I have felt colleagues dismiss the importance of LGBT identity and advocacy: 'here we go again'. I am always shocked that people kind of think that we've conquered the whole sexuality issue and there is no discrimination' (social worker). 
Please cite as: Hafford-Letchfield, T., Cocker, C., Rutter, D., Manning, R., McCormack, K (2020) Doing the right thing and getting it right: Professional perspectives in social work on supporting parents from gender diverse communities. International Journal of Transgender Health. Published online first https://www.tandfonline.com/doi/full/10.1080/26895269.2020.1831417

This inability to offer a nuanced response to trans individuals, particularly in adult social care, was attributed to a system in which social work is unable to initiate tailored interventions. Given the constant streamlining of services for efficiency, any specialised support had been "shaved to kind of like the absolute margins". The emphasis on care coordination role where people are linked to services and their care monitored by unqualified staff complicated potential for sensitive provision. One of the trans parents interviewed commented on the tendency for professionals to assume they can 'see' a person's gender and therefore make assumptions.

One participant gave detailed examples of a family placement assessment with a trans applicant which brought to life many of the complexities involved in building trust between the assessor and the applicant. The applicant was a trans single woman in her early 30 s who approached an adoption service in an diverse inner city local authority Her application was successful and a match with a child was made. However, the placement did not proceed as she voluntarily withdrew her application. Her feedback to the Panel was that she expected never to have been accepted and having gone through the process, she realised that she was now not sure about going ahead.

The independent social worker describing this work had extensive experience in lesbian and gay adoption and was recruited specifically by the Local Authority to conduct the assessment. She articulated the challenges and dilemmas in 'really willing it to work' and simultaneously being cautious of her own biases. The complexity of the assessment required independent supervision to observe the process and support decision-making with lots of stops and starts. It involved the social worker providing family therapy type-work with the applicant's birth family (with her consent) where a protracted process of working through unresolved grief and 
Please cite as: Hafford-Letchfield, T., Cocker, C., Rutter, D., Manning, R., McCormack, K (2020) Doing the right thing and getting it right: Professional perspectives in social work on supporting parents from gender diverse communities. International Journal of Transgender Health. Published online first https://www.tandfonline.com/doi/full/10.1080/26895269.2020.1831417

loss was a key issue. Whilst the social worker was conscious of the need to stay focussed on the purpose of assessment, she felt that working through emotions was crucial to the potential adopter's wellbeing and could support a more successful placement. She disclosed her own sexual identity to the person to build trust. This was not usual practice and she experienced coming out as a dilemma.

Whilst just one assessment, as an example, this assessment highlighted that adoption and fostering assessments might require extraordinary time and resources that some local authorities may not be willing or able to allocate. This example reflects good practice through an ethical and transparent approach but highlights the real investment needed to conduct a fair and constructive assessment. The assessor articulated the need for consistent competent supervision. She described how she sought to create an environment within the assessment to air challenges and provide opportunities to work through the applicant's additional support needs. Given the close working relationship that had developed between the social worker and applicant, the social worker initially felt angered by the decision of the applicant, but recognised the complex dynamics at play and the essential learning for the local authority:

"For me it links to the kind of gay marriage conversation, as you start to get entitlement to equality, it is sometimes tempting to think that you should go for everything you've got a right to have. And sometimes maybe, it's difficult in the cold light of day to assess whether or not that is really right for you" (independent adoption assessor)

Other participants with direct experience of assessment and decision-making about adoption and fostering recognised the potential for children's placement in families with TNB parents and the value of diverse parenting for children's needs. They also recognised the importance 
Please cite as: Hafford-Letchfield, T., Cocker, C., Rutter, D., Manning, R., McCormack, K (2020) Doing the right thing and getting it right: Professional perspectives in social work on supporting parents from gender diverse communities. International Journal of Transgender Health. Published online first https://www.tandfonline.com/doi/full/10.1080/26895269.2020.1831417

of a robust assessment that addressed and evidenced prospective adopters and foster carers potential as parents.

"There's only really one challenge.... which is about ensuring assessors are confident to explore rigorously people's families, their histories and their own circumstances and how they're going to parent and not be sort of pushed away from difficult areas because of the, maybe potential defensiveness of those being assessed. So it's about an empathic, rigorous, confident exploration where you're confident enough to say -I really don't understand about this, could you tell me more about that" (Panel Chair)

Reiterating the potential of a strengths-based approach and value-based framework in family social work, there was a tension noted for assessors, on their capacity to enter the other person's world and to try to understand it from their perspective, whilst ensuring that the focus remained on the prospective applicant's capacity to care and enable reparatory care for a child. They also recognised a substantial gap in the recruitment, supervision, assessment and support of parents from the LGBT community overall, and the marked gap for TNB members.

\footnotetext{
"Given the focus on the child, it's important to focus on the assessment, supervision and support of potential parents and not getting side-tracked particularly by the transgender issues 'neither over focusing, nor ignoring it" (Panel Chair)
}

Key participants suggested that only close supervision and co-working of active cases, would foster these competencies between workers within the same agency, rather than discussing TNB issues at an abstract level. Participants suggested that this might also have ramifications for additional work involving training with fostering and adoption panel members, many of 
Please cite as: Hafford-Letchfield, T., Cocker, C., Rutter, D., Manning, R., McCormack, K (2020) Doing the right thing and getting it right: Professional perspectives in social work on supporting parents from gender diverse communities. International Journal of Transgender Health. Published online first https://www.tandfonline.com/doi/full/10.1080/26895269.2020.1831417

whom are independent members. As illustrated earlier, giving time and opportunities for members to build trust and confidence in the thoroughness of the assessment, as well as to air issues and question their own assumptions, was an important process in ensuring that the panel's quality assurance role was focussed on the applicants ability to care for a child in public care.

"I would really recommend that you have a session with the (adoption) panel, where you put forward your interim position and you allow people to be challenging, critical, questioning.... and we did allow some freedom in the panel to just be curious and ask silly questions that you would be worried about asking in front of an applicant" (independent adoption assessor)

A number of other participants reflected on how to improve and strengthen practice with trans parents; they gave emphasis on adopting a narrative approach within assessments to focus on the trans person's own stories and to acknowledge stress and distress. Participants reflected on the importance of social workers taking an advocacy role with other care agencies where required, but also needing to 'put its own house in order'.

“(we) really need to work with people with lived experience, hear their stories, to understand as deeply as we can who they are, how they've got to where they are, their reflections, what's been helpful, matters to them and how we can support them to achieve the things they want at whatever stage of life they are at" (social worker, mental health)

A further example of advocacy from participants cited a residential parenting assessment of a new parent who had given birth and intended to transition. This assessment went well despite 
Please cite as: Hafford-Letchfield, T., Cocker, C., Rutter, D., Manning, R., McCormack, K (2020) Doing the right thing and getting it right: Professional perspectives in social work on supporting parents from gender diverse communities. International Journal of Transgender Health. Published online first https://www.tandfonline.com/doi/full/10.1080/26895269.2020.1831417

social services conveying an expectation that the assessment would carry a negative outcome. The team, having had little training, took time to inform themselves and found the assessment to be a positive learning experience for the agency. In the multidisciplinary environment, however, medical staff had labelled the parent's natural anxiety about breastfeeding and attributed this to their instability in their gender identity. These factors resulted in additional complicated stress to the parent.

Finally, participants identified significant problems related to language and terminology. They described practitioners as being nervous about saying the wrong thing, being avoidant, and not having a grasp of the importance of using the correct pronouns. An example where the practitioner identified that the service user wished to use ' $M x^{\prime}$ ', the limited online data recording settings made it impossible to record this for future contact. These potential microaggressions hindered trust building in improving access to services. Conflating gender diversity with sexual diversity was another common experience.

\section{Discussion}

This study explored the perspectives of a diverse range of practitioners on how they advocated supporting parents from gender diverse communities. Findings show the need for step change across the health and social care sectors, with many similar themes presented across different services in the data.

The data highlighted salient barriers to improving practice with TNB parents at the organisational and systems level. Firstly there is a significant role for leadership for managers, commissioners, educators and practitioners to promote the rights and needs of service users who are gender diverse with social work and social care services. Secondly, 
Please cite as: Hafford-Letchfield, T., Cocker, C., Rutter, D., Manning, R., McCormack, K (2020) Doing the right thing and getting it right: Professional perspectives in social work on supporting parents from gender diverse communities. International Journal of Transgender Health. Published online first https://www.tandfonline.com/doi/full/10.1080/26895269.2020.1831417

there is a dearth of training and the confidence and ability to deliver this well and coherently. Crucial to addressing these is the need to foster inclusive networks with TNB communities and develop structures and processes which encourage their active participation to address service access, delivery and evaluation. Finally, any initiatives to improve practice will need to recognise the challenges of cultural and political climate for change given the absence of a coherent government framework for supporting TNB inclusion reflected in legislation, policy, monitoring and development of progressive measures to promote TNB rights in the UK.

Despite some of these challenges, there appears to be an appetite for change. Participants recognised the labelling and stigmatising of everyday parenting challenges and the need to promote support to focus on promoting relationships, love, care and intimacies regardless of gender and other identities.

There are varieties of ways in which services can address many of the issues raised. One option is to ensure that all workers have the requisite skills and knowledge to work effectively with different types of families that require support. One participant's comments about the 'challenge' of TNB discourses compared to other forms of diversity: "if you took away the word trans...", attempts to acknowledge the diversities inherent within society that all professionals deal with every day, and should be able to respond to in their practice.

However, the idea of 'swapping out' difference sets up a danger of assimilation of diversity, which erases the specific needs of TNB communities and individuals. Where confusion and uncertainty arises for practitioners when working with trans people in many professional services, it is important for these to be specifically addressed and understood in the context of their specificity rather than compared to different issues experienced by other groups. 
Please cite as: Hafford-Letchfield, T., Cocker, C., Rutter, D., Manning, R., McCormack, K (2020) Doing the right thing and getting it right: Professional perspectives in social work on supporting parents from gender diverse communities. International Journal of Transgender Health. Published online first https://www.tandfonline.com/doi/full/10.1080/26895269.2020.1831417

Similarly, comparison between different diversities creates a hierarchy of difference, which is also unhelpful (Authors own; Pearce et al, 2020). The challenge is to encourage practitioners to think through and acknowledge the specific challenges faced by specific groups because of their experiences.

Another option is to adopt specialist models where services have champions/coordinators trained to act as advisors/advocates for trans families to cascade knowledge and skills throughout the organisation; or helping all staff develop their cultural competence to adapt their practice using mainstream tools, such as family genograms, to capture all family relationships and to enable positive discussion about family issues. There are also specialist tools in specific service areas such as fostering and adoption (Authors own 2010), which can be utilised across the practice spectrum. The case study provided an example of where an experienced practitioner undertook a specialist assessment. Understanding the specific challenges faced by the prospective adopter helped the assessor make sense of the prospective adopter's decision to withdraw from the adoption application, even though she had been approved. The depth of experience and knowledge assisted the practitioner in ensuring that the skill base she utilised whilst conducting the assessment was not discriminatory. However, because fostering and adoption assessments with TNB applicants are still rare, the voice of applicants that captures specific information about the differences in their motivations, rationale and contexts for applications is still developing. It is however a good example of how a specialist assessment can gather data that can be used to inform the development of general practices for that specific community over time (Authors own, 2010; Brown and Rogers, 2020)

\section{Limitations}


Please cite as: Hafford-Letchfield, T., Cocker, C., Rutter, D., Manning, R., McCormack, K (2020) Doing the right thing and getting it right: Professional perspectives in social work on supporting parents from gender diverse communities. International Journal of Transgender Health. Published online first https://www.tandfonline.com/doi/full/10.1080/26895269.2020.1831417

Those we interviewed were more likely to be motivated, curious and interested and the study provided a snapshot of current practice only. As an exploratory study, there was insufficient data to develop an intersectional analysis of practitioner's experiences. Although our sample of professional staff came from metropolitan areas across England, the majority of participants were white.

\section{Conclusion:}

This exploratory study involved identifying areas of consensus across practitioners working in a number of health and social care settings to inform recommendations for practitioners working with TNB families. These included benchmarked areas of development, including highlighting areas of good practice, driven by individual professionals committed to making a difference to services for TNB families. However, this is set against a number of systemic and organisational challenges, which reinforce the dangers of heteronormative and cisnormative polices and frameworks continuing to govern practice. There are a number of options for moving forward. Next steps should involve liaison with TNB communities on strategies that could be 'decidable and executable' when going forward with further development work (Shekelle et al., 2012, p 7). Ultimately, good practice across health and social care organisation is about recognising and respecting the diversity of families and all their constituent members. This requires all professionals to take an active role to educate themselves; be active in reaching out to parents and be authentic in engagement activities so as to address diversity ensures services to all are inclusive and responsive. Focusing on human rights, tailoring work to the specific needs of individuals and affirming the diversity of family life require professionals to take active responsibility in doing the right thing and doing it right. 
Please cite as: Hafford-Letchfield, T., Cocker, C., Rutter, D., Manning, R., McCormack, K (2020) Doing the right thing and getting it right: Professional perspectives in social work on supporting parents from gender diverse communities. International Journal of Transgender Health. Published online first https://www.tandfonline.com/doi/full/10.1080/26895269.2020.1831417

Disclosure of conflicts: The authors declare they have no conflict of interest

Informed consent: Informed consent was obtained from all individual parties included in the study. 
Please cite as: Hafford-Letchfield, T., Cocker, C., Rutter, D., Manning, R., McCormack, K (2020) Doing the right thing and getting it right: Professional perspectives in social work on supporting parents from gender diverse communities. International Journal of Transgender Health. Published online first https://www.tandfonline.com/doi/full/10.1080/26895269.2020.1831417

References

Adams, N., Pearce, R., Veale, J., Radix, A., Castro, A., \& Thom, K. (2017). Guidance and Ethical Considerations for Undertaking Transgender Health Research and Institutional Review Boards Adjudicating this Research. Transgender Health, 2(1), 165-175. doi:10.1089/TRGH.2017.0012

Alleyn, C., \& Jones, R. L. (2010). Queerying care: Dissident trans identities in health and social care settings. In R. L. Jones \& R. Ward (Eds.), LGBT issues : looking beyond categories - Policy and practice in health and social care: 10 (pp. 56-68): Dunedin Academic.

Bowling, J., Dodge, B., \& Bartelt, E. (2017). Sexuality-related communication within the family context: experiences of bisexual parents with their children in the United States of America. Sex Education, 17(1), 86-102. doi:10.1080/14681811.2016.1238821

Brown, C., \& Rogers, M. (2020). Removing gender barriers: Promoting inclusion for trans and nonbinary carers in fostering and adoption. Child and Family Social Work, 25(3), 594-601. doi:10.1111/cfs.12731

Communities Analytical Services. (2013). Scottish government equality outcomes: Lesbian, gay, bisexual and transgender (LGB\&T) evidence review. In: The Scottish Government.

Craig, S. L., lacono, G., Paceley, M. S., Dentato, M. P., \& Boyle, K. E. H. (2017). Intersecting Sexual, Gender, and Professional Identities Among Social Work Students: The Importance of Identity Integration. Journal of Social Work Education, 53(3), 466-479. doi:10.1080/10437797.2016.1272516

Gapka, S., \& Raj, R. (2003). Trans health project: A position paper and resolution adopted by the Ontario Public Health Association. Retrieved from Toronto: http://www.opha.on.ca/our voice/ppres/papers/2003-06 pp.pdf

Garthe, R. C., Hidalgo, M. A., Hereth, J., Garofalo, R., Reisner, S. L., Mimiaga, M. J., \& Kuhns, L. (2018). Prevalence and Risk Correlates of Intimate Partner Violence Among a Multisite Cohort of Young Transgender Women. LGBT Health, 5(6), 333-340. doi:10.1089/lgbt.2018.0034

Golombok, S., Mellish, L., Jennings, S., Casey, P., Tasker, F., \& Lamb, M. (2014). Adoptive gay father families: Parent-child relationships and children's psychological adjustment. Child Development, 85(2), 456-468. doi:10.1111/cdev.12155

Golombok, S., \& Tasker, F. (1996). Do parents influence the sexual orientation of their children? Findings from a longitudinal study of lesbian families. Developmental Psychology, 32, 3-11. doi:10.1037/0012-1649.32.1.3

Government Equalities Office. (2016). Government response to the Women and Equalities Committee Report on Transgender Equality.. In. London: HMSO.

Hicks, S. (2014). Deconstructing the Family. In C. Cocker \& T. Hafford-Letchfield (Eds.), Rethinking Anti-Discriminatory and Anti-Oppressive Theories for Social Work Practice. Basingstoke: Palgrave.

Hines, S. (2006). Intimate Transitions: Transgender Practices of Partnering and Parenting. Sociology, 40(2), 353-371. doi:10.1177/0038038506062037

Hines, S. (2007). Transgendering care: Practices of care within transgender communities. Critical Social Policy, 27(4), 462-486. doi:10.1177/0261018307081808

House of Commons Women and Equalities Committee (Producer). (2016). Transgender Equality, First Report of Session 2015-16: Report. Retrieved from https://publications.parliament.uk/pa/cm201516/cmselect/cmwomeq/390/390.pdf 
Please cite as: Hafford-Letchfield, T., Cocker, C., Rutter, D., Manning, R., McCormack, K (2020) Doing the right thing and getting it right: Professional perspectives in social work on supporting parents from gender diverse communities. International Journal of Transgender Health. Published online first https://www.tandfonline.com/doi/full/10.1080/26895269.2020.1831417

Hudson-Sharp, N. (2018). Transgender awareness in child and family social work education: Research report. In. London: National Institute of Economic and Social Research, Department of Education.

Hudson-Sharp, N., \& Metcalf, H. (2016). Inequality amongst lesbian, gay, bisexual and transgender groups in the UK: an evidence review. In. London: NIESR.

Lev, A. (2004). Transgender emergence: Therapeutic guidelines for working with gender-variant people and their families. Binghampton, New York: Howarth Press.

Marshall, Z., Welch, V., Thomas, J., Brunger, F., Swab, M., \& Shemilt, C. (2017). Documenting research with transgender and gender diverse people: protocol for an evidence map and thematic analysis. Systematic Reviews, 6(1), 1-6. doi:10.1186/s13643-017-0427-5

Mitchell, M., \& Howarth, C. T. r. r. M., England: Equality and Human Rights Commission. (2009). Trans Research Review. In. Manchester: Equality and Human Rights Commission.

NHS England. (2017). Consultation on Gender Identity Services for Adults. Retrieved from https://www.engage.england.nhs.uk/survey/gender-identity-services-for-adults/. https://www.engage.england.nhs.uk/survey/gender-identity-services-for-adults/

Obedin-Maliver, J., \& Makadon, H. J. (2016). Transgender men and pregnancy. Obstetric Medicine (1753-495X), 9(1), 4-8. doi:10.1177/1753495X15612658

Office for National Statistics. (2017). Gender identity update. Retrieved from https://www.ons.gov.uk/methodology/classificationsandstandards/measuringequality/gend eridentity/genderidentityupdate

Orr, K., \& Bennett, M. (2009). Reflexivity in the co-production of academic-practitioner research. Asia Pacific Journal of Marketing and Logistics, 4(1), 85-102. doi:10.1108/17465640910951462

Patterson, C. J. (2017). Parents' sexual orientation and children's development. Child Development Perspectives, 11(1), 45-49. doi:10.1111/cdep.12207

Pearce, R. (2020). A Methodology for the Marginalised: Surviving Oppression and Traumatic Fieldwork in the Neoliberal Academy. Sociology, 54(4), 806-824. doi:10.1177/0038038520904918

Pearce, R., Moon, I., Gupta, K., \& Steinberg, D. (2020). The Emergence of Trans: Cultures, Politics and Everyday Lives. In. Abingdon: Routledge.

Pearce, R., \& White, F. (2019). Beyond the pregnant man: representing trans pregnancy in A Deal With The Universe. Feminist Media Studies, 19(5), 764-767. doi:10.1080/14680777.2019.1630925

Poly, K., \& Poly, R. (2014). Parenting. In L. Erickson-Schroth (Ed.), Trans bodies, trans selves: A resource for the transgender community (pp. 390-405). New York: Oxford University Press.

Pyne, J., Bauer, G., \& Bradley, K. (2015). Transphobia and Other Stressors Impacting Trans Parents. Journal of GLBT Family Studies, 11(2), 107. doi:doi.org/10.1080/1550428X.2014.941127

$\mathrm{R}$ (on the application of McConnell and another) v Registrar General for England and Wales, (2019).

Stotzer, R., Herman, J., \& Hasenbush, A. (2014). Transgender parenting: A review of existing research. Retrieved from Los Angeles: https://escholarship.org/uc/item/3rp0v7qv

Tasker, F., \& Gato, J. (2020). Gender Identity and Future Thinking About Parenthood: A Qualitative Analysis of Focus Group Data With Transgender and Non-binary People in the United Kingdom. Frontiers in Psychology, 11. doi:10.3389/fpsyg.2020.00865

Vincent, B. W. (2018). Studying trans: recommendations for ethical recruitment and collaboration with transgender participants in academic research. Psychology \& Sexuality, 9(2), 102-116. doi:10.1080/19419899.2018.1434558

Walls, N. E., Kattari, S. K., \& DeChants, J. (2018). Transmasculine Spectrum Parenting: Beyond a Gendered Fatherhood. Social Work Research, 42(3), 223-236. doi:10.1093/swr/svy020 
Please cite as: Hafford-Letchfield, T., Cocker, C., Rutter, D., Manning, R., McCormack, K (2020) Doing the right thing and getting it right: Professional perspectives in social work on supporting parents from gender diverse communities. International Journal of Transgender Health. Published online first https://www.tandfonline.com/doi/full/10.1080/26895269.2020.1831417

Walls, N. E., Kattari, S. K., Speer, S. R., \& Kinney, M. K. (2019). Transfeminine Spectrum Parenting: Evidence from the National Transgender Discrimination Survey. Social Work Research, 43(3), 133-144. doi:10.1093/swr/svz005

White, R. F. (2018). Trans Pregnancy: An International Exploration of Transmasculine Practices of Reproduction - Law and Policy Review. In. London: University of Westminster. 